\title{
El patrimonio inmaterial y la construcción de paz: la actividad del Centro de Memoria, Paz y Reconciliación de Bogotá D.C.
}

José Antequera Guzmán | Centro de Memoria, Paz y Reconciliación

URL de la contribución <www.iaph.es/revistaph/index.php/revistaph/article/view/4941>

\section{RESUMEN}

En este escrito se describe la labor del Centro de Memoria, Paz y Reconciliación de Bogotá (Colombia), como un proyecto funcional a la construcción de paz a partir de sus elementos particulares. Estos han sido resultado de la decisión consciente de cuestionar retóricas instaladas sobre la labor que correspondería a los llamados sitios de la memoria, pero disfuncionales, directamente inconvenientes y poco efectivas. El abordaje de esos elementos particulares y perspectivas de actuación es un aporte al conocimiento sobre la cuestión del patrimonio inmaterial para la resolución de conflictos, así como un referente de análisis para otras experiencias en curso o por construir.

\section{Palabras clave}

Bogotá (Colombia) | Centro de Memoria, Paz y Reconciliación | Conflictos | Memoria | Patrimonio inmaterial | 


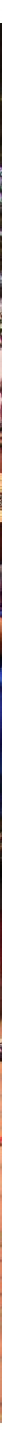

Ceremonia de armonización de pueblos indígenas (2018) | foto todas las imágenes son propiedad del Centro de Memoria, Paz y Reconciliación 


\section{EL CENTRO}

El Centro de Memoria, Paz y Reconciliación de Bogotá D.C. se comenzó a construir en el año 2008 como parte de un plan de desarrollo para la capital de Colombia de corte progresista. Su construcción inicialmente sintetizaba la inquietud de la coalición de gobierno alternativo en la capital del país por reivindicar la experiencia histórica de exclusión y de violaciones a los derechos humanos, siendo una coalición con muy poca experiencia de gobierno y que reunía a quienes habían disputado el poder al bipartidismo liberal-conservador a lo largo del siglo XX: agrupaciones políticas de izquierda, en algunos casos vinculadas con guerrillas que habían firmado pactos de paz, sindicatos y diferentes movimientos sociales, entre otros. Tal coalición pretendía representar especialmente a los grupos sociales que históricamente habían sufrido la mayor cantidad y las más graves violaciones a los derechos humanos por razones políticas en el país por haber defendido, y aún lo hacían, la posibilidad de una solución dialogada del conflicto armado interno en Colombia.

Tres años antes, desde el año 2005, en el país se había desarrollado un proceso nacional de desmovilización de grupos paramilitares que significó la afirmación de que los derechos de las víctimas debían ser insoslayables de cualquier proceso de paz. Así, gracias a la incidencia de un movimiento creciente, que vio en la construcción del Centro en la capital del país una oportunidad de fortalecimiento de sus demandas sin renunciar al gran objetivo de la solución política del conflicto, lo que inicialmente se había proyectado como una obra pequeña, se convirtió en la primera gran obra emprendida de su tipo, ligada además a las conmemoraciones por el Bicentenario de la

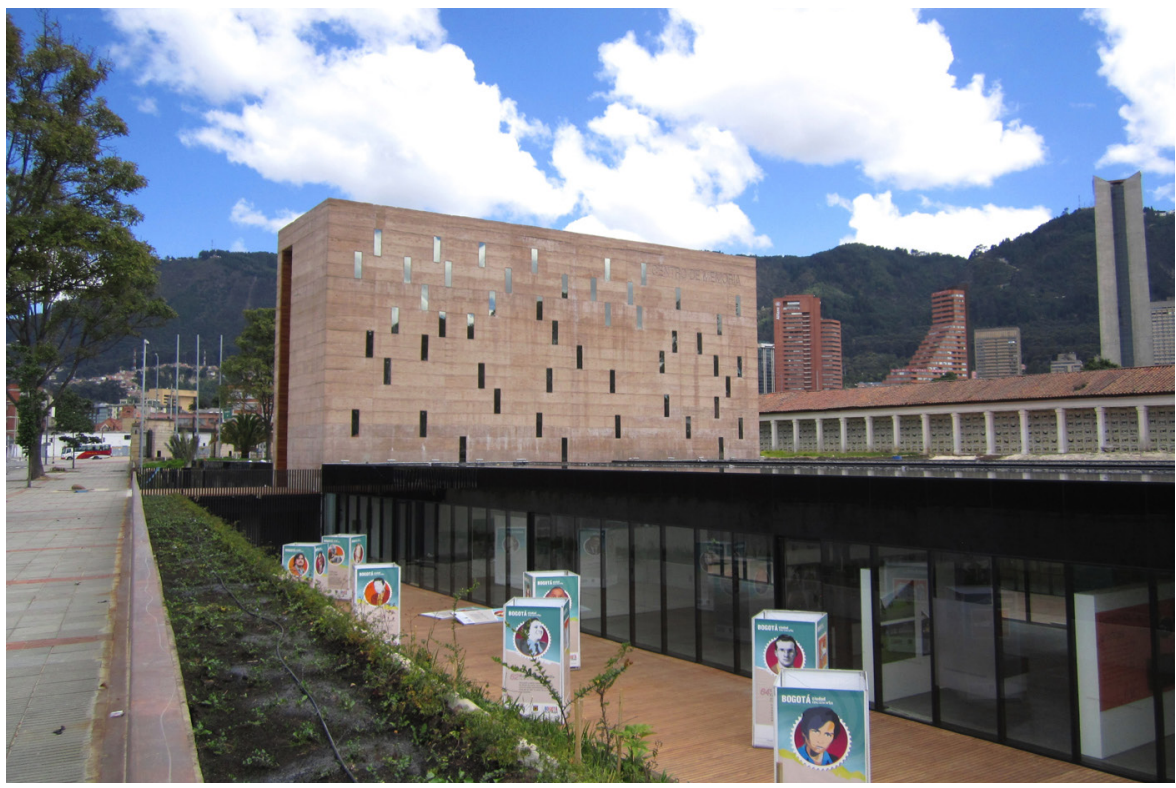


Independencia con el nombre del Centro del Bicentenario, Memoria, Paz y Reconciliación. Esta sería levantada a partir de un gran concurso arquitectónico en un lote de miles de metros cuadrados con auditorio para 300 personas, aulas múltiples, salas de exposición y un Memorial por la vida, todo ello en un área de gran valor patrimonial por ser antiguo cementerio de pobres y NN (personas sin identificar).

El Centro de Memoria, Paz y Reconciliación sería además un proyecto dentro de la categoría de los llamados sitios de memoria o sitios de conciencia, como los campos de concentración preservados como patrimonio de la experiencia de las guerras, las dictaduras, los conflictos internos y las graves violaciones a los derechos humanos. Centros de tortura y detención en América Latina, como el espacio de la antigua Escuela de Mecánica de la Armada ESMA en Argentina, Villa Grimaldi en Chile y otros tantos, se reúnen en la Coalición Internacional de Sitios de Conciencia y en la Red Latinoamericana de Lugares de Memoria, en la que el Centro de Memoria, Paz y Reconciliación encontraba inspiración y alianzas.

\section{MEMORIA, PATRIMONIO INMATERIAL Y CONSTRUCCIÓN DE PAZ}

Como en muchos lugares del mundo, la memoria para la paz como problema de políticas que incluyen el asunto de la preservación y usos del patrimonio cultural inmaterial tiene su historia particular.

En un amplísimo escenario de múltiples formas de producción de historia, estas políticas de usos del pasado en Estados democráticos occidentales surgieron ligadas al referente de la conmemoración del Holocausto y la búsqueda de lecciones universales desde allí, así como a los procesos de descolonización del sur que suponen el reclamo de existencia nacional y/o identitaria de lugares tratados como periféricos y de luchas que reclaman su lugar en la formación de la democracia misma (Rufe 2010).

En la Colombia de 2005, estas vertientes se cruzan en la resistencia al proyecto de impunidad para el paramilitarismo, responsable de la mayor cantidad de violaciones de los derechos humanos al menos desde los años 80 , con la afirmación de los derechos de las víctimas del conflicto armado interno ya degradado, y la demanda desde aquellos lugares en los que se habían ejercido masacres y grandes actos de despojo de tierras como lugares "abandonados por el Estado" considerados en el mapa nacional sobre todo a partir de las tragedias del llamado orden público en la periferia.

En este contexto, "en medio del conflicto", era difícil, si no imposible, la identificación e intervención de lugares que hubieran funcionado como escenarios de ocurrencia de hechos. Así, la memoria debería ejercerse, porque así 

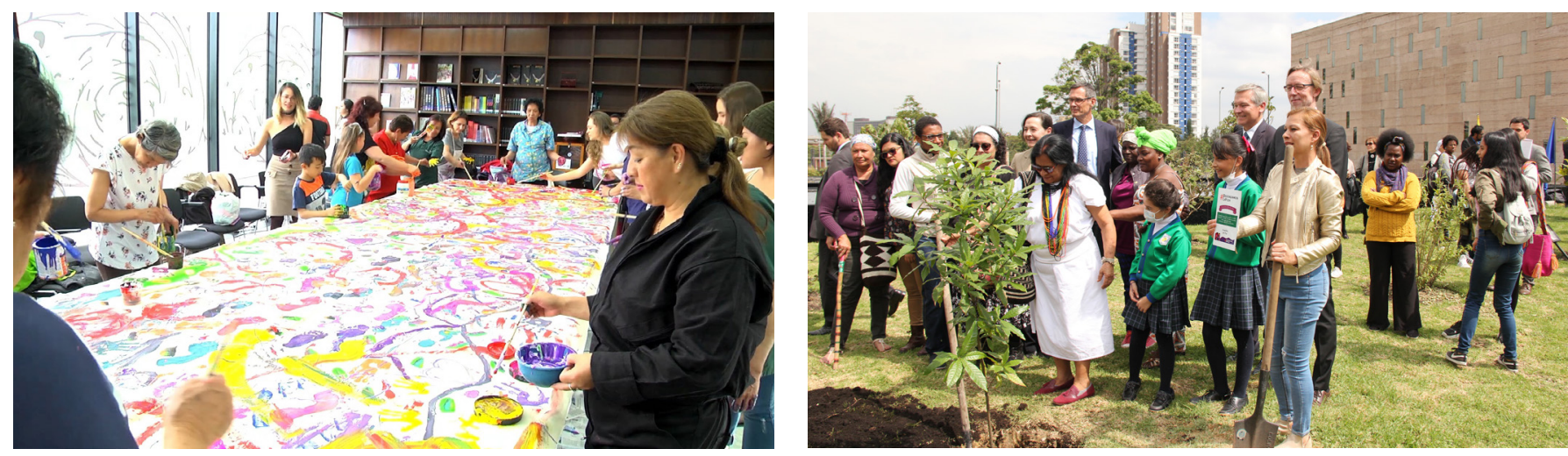

Galería Itinerante Bogotá Ciudad memoria. A la izquierda, actividad pedagógica (2018); a la derecha, siembra de embajadas de la Unión Europea en homenaje a líderes sociales asesinados después de la firma del acuerdo de paz (2020)

imponían las circunstancias en lugares diferentes, ocupados o construidos, donde circulara un acervo de experiencia y documentación que, de facto, vendría a ser reconocido como patrimonio inmaterial vinculado con investigaciones en desarrollo que serían de memoria histórica si se basaban fundamentalmente en testimonios de víctimas.

Mientras los movimientos sociales desarrollaban múltiples iniciativas, a nivel oficial se iniciaron proyectos desde donde se pretendía el reconocimiento autorizado de lo memorable y, en ese sentido, pudiendo ser incluido en el Patrimonio, con mayúscula. Así, por iniciativa del gobierno nacional, se creó en 2005 el Grupo de Memoria Histórica para investigar "el origen y desarrollo de los grupos armados organizados al margen de la Ley". Por iniciativa de la coalición de gobierno en Bogotá desde el 2008, se impulsó la construcción del Centro de Memoria, Paz y Reconciliación. Emulando la experiencia de la capital, se inició la construcción de la Casa Museo de Memoria de Medellín. Y como gran think tank avalado por el Estado para la producción de contenidos, se creó en 2011 el Centro Nacional de Memoria Histórica gestionado por algunos de los intelectuales vivos más destacados en el estudio de la violencia y el conflicto.

Tales iniciativas oficiales aportaron a la construcción de un campo de acontecimientos memorables, mayormente iluminados dentro del conjunto que llamaríamos patrimonio inmaterial, con sus significados e implicaciones diferentes, pero con el común denominador de su carácter como argumentos para la necesidad de la paz entre el gobierno y las guerrillas.

La memoria, aunque se tratara de un concepto muy amplio vinculado a la cultura, era entendida como el recuerdo de las víctimas definidas como experimentadoras directas de dolor y sufrimiento y por ello voceras legítimas exclusivas del pasado. La paz debiera ser el resultado, sobre todo, de la satisfacción de los derechos de las víctimas así consideradas sobre la afirmación de que diferentes países que habían emprendido procesos de transición en el mundo habían caído de nuevo en la violencia fundamentalmente 


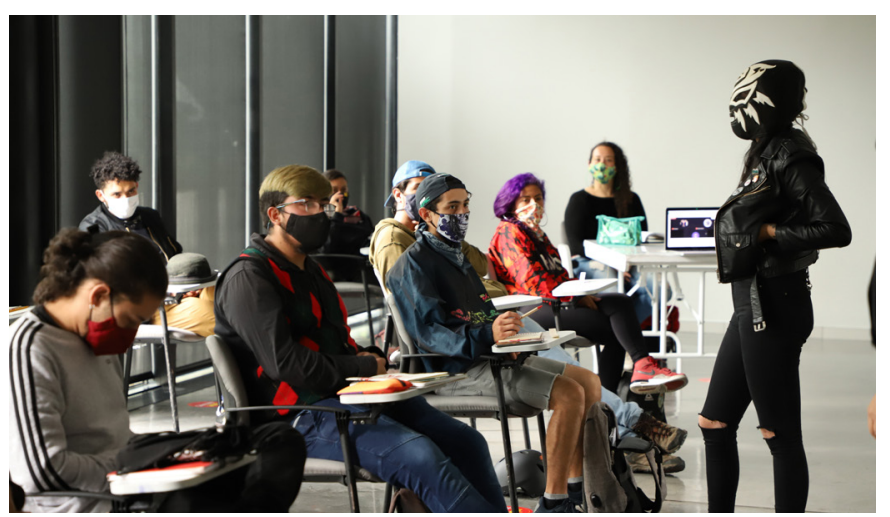

por no haber avanzado realmente en esa satisfacción de verdad, justicia y reparación para la no repetición. Las políticas de memoria, como islas en las políticas culturales, debieran ser conjuntos de medidas emanadas de tales presupuestos para un tipo de patrimonialización aparte del conjunto, hacia la paz como fin de las confrontaciones armadas.

Hoy tenemos razones para cuestionar estos planteamientos, sin desconocer las afirmaciones ciertas que contienen y la importancia que representan como justificación de políticas oficiales que no pretendemos desmontar.

Claramente la memoria como problema público es inherente a la sociedad visto el mundo como un foro para la acción, como diría Jordan Peterson (2020). Los movimientos sociales, sobre todo desde que el llamado occidente se marca por aquello de que "todo lo sagrado se hace profano y todo lo sólido se desvanece en el aire", han impulsado la reivindicación del reconocimiento como experiencia histórica y efectos presentes del curso del progreso modernizante, con su explotación, sus despojos, sus opresiones, sus violencias, y claro, la oposición frente al mismo.

En ese foro para la acción, que la memoria signifique legitimidad exclusiva de las víctimas a partir de la experiencia de sufrimiento con respecto a los períodos de violencia política, conflicto o dictadura, y que la repetición o no de las marcas de estos períodos dependa fundamentalmente de la satisfacción de derechos reconocidos para éstas, resulta problemático.

Desde una mirada democrática, lo memorable en la memoria no es solo el dolor. También son memorables, necesariamente memorables, la transgresión, la resistencia frente a las violaciones a los derechos humanos y el aporte constructivo a la convivencia, entre otras (Ricard 2009).

A su vez, la construcción de sociedades democráticas de manera sustantiva supone la igualdad política que resulta incompatible con el reclamo de legi-
A la izquierda, laboratorio artístico de co-creación (2020), a la derecha, audiencia de la Corte Interamericana de Derechos Humanos del caso de la periodista Jineth Bedoya (2021) 


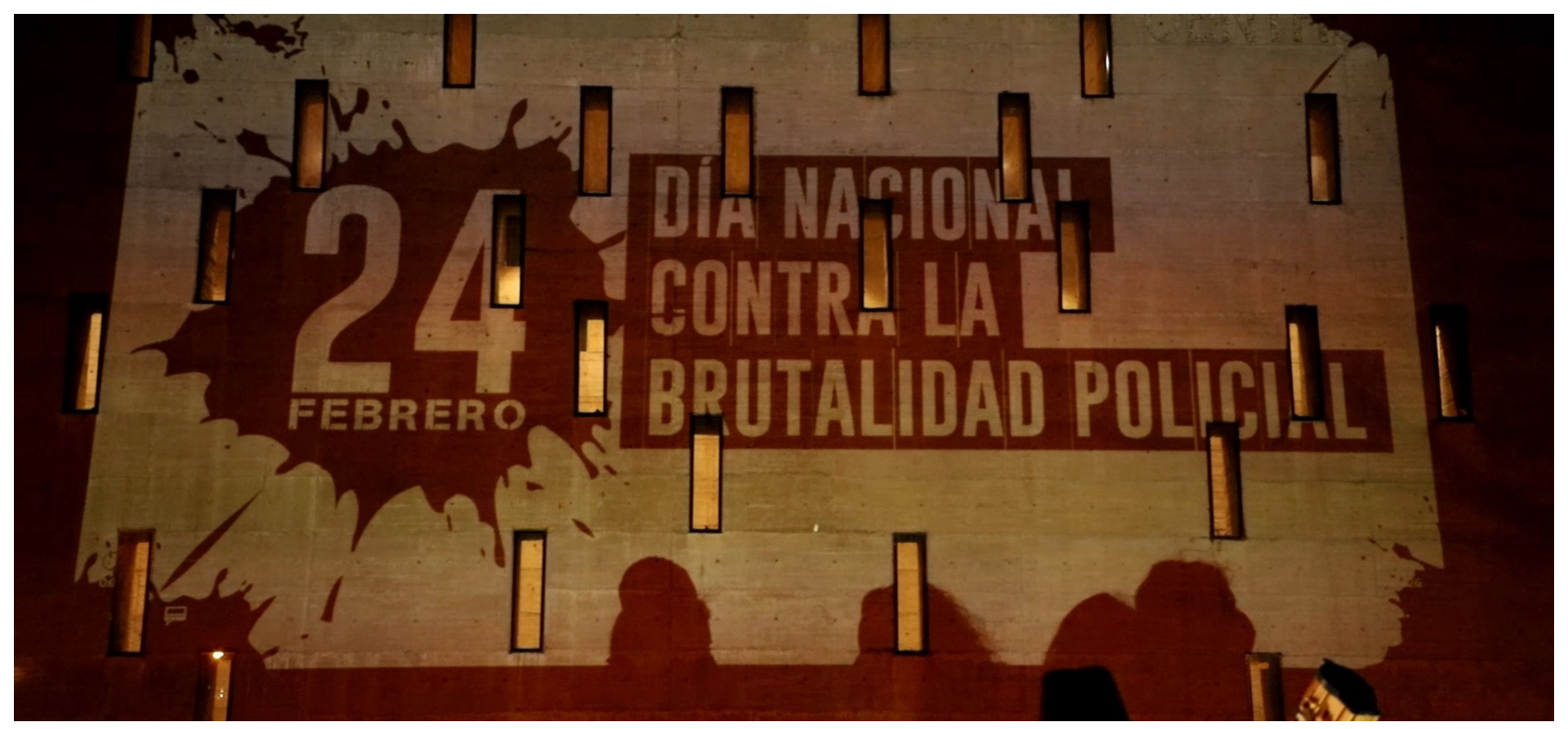

Conmemoración del Día Nacional contra la Brutalidad Policial (24 de febrero 2021)

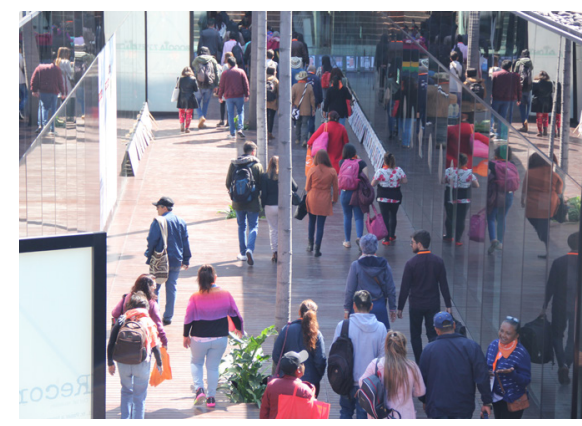

Encuentro del Movimiento Nacional de Víctimas de Crímenes de Estado (2020) timidad exclusiva para la acción democrática Butler 2020), lo que no implica desconocimiento de la legitimidad moral soportada en la experiencia para la exigencia de derechos. Más allá, lo que indica la evidencia de las experiencias de diferentes países con respecto a la superación o repetición de las marcas de la violencia, el conflicto y las dictaduras, es que con diferentes niveles de satisfacción o de los derechos de las víctimas, es fundamental que los procesos de transición impliquen transformaciones que rebasen los mandatos de la justicia transicional de modo que puedan implicar soluciones a problemas estructurales que no se refieren solo a quienes han sufrido acontecimientos específicos.

Digo más. En la medida en que la memoria puede ser también un instrumento de afirmación de la razón de la guerra, como lo ha sido, el impulso de la memoria para la paz es necesariamente la promoción de la cultura de lo común y de las causas comunes humanas sobre el reconocimiento de las diferencias, y no solo del reconocimiento de las diferencias, por ejemplo, por intensidad de sufrimiento.

Podemos decir que el Centro de Memoria, Paz y Reconciliación de Bogotá D.C. ha podido desarrollarse en debate permanente con la retórica de la que hablo considerando muchas visiones críticas, teniendo siempre una perspectiva amplia. Mientras otras instituciones, como el Centro Nacional de Memoria Histórica, que fue creado bajo un marco regulatorio detallado (Ley 1448 de 2011) donde se habían concentrado las expectativas de corrección política del gobierno nacional, el Centro de Bogotá pudo ser un lugar abierto 


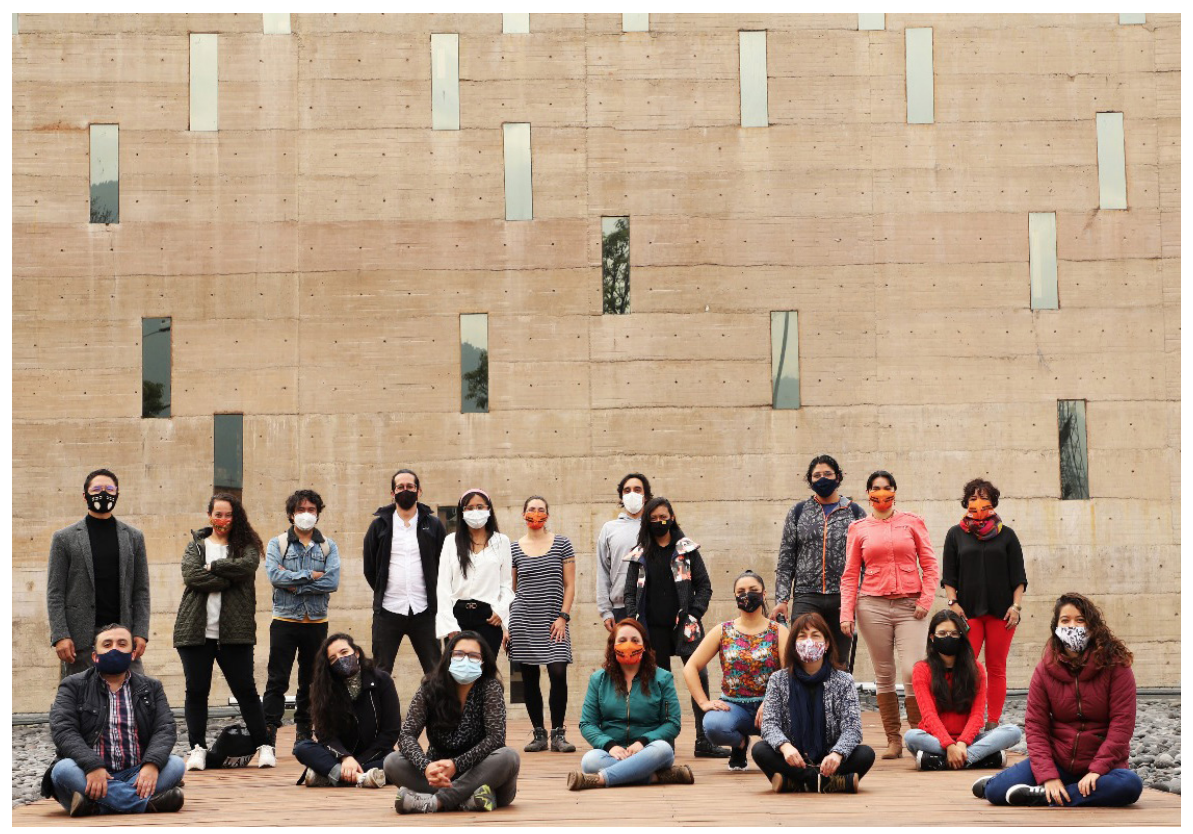

Equipo del Centro de Memoria, Paz y Reconciliación de Bogotá (2020)

a debates y activismos, no solo para los sectores y movimientos progresistas, sino para la academia.

\section{LA LABOR DEL CENTRO}

Siguiendo lo anterior, el Centro de Memoria, Paz y Reconciliación se organiza por líneas de trabajo cuyos proyectos reflejan el interés por rebasar la exhibición de "lo ocurrido en el pasado como sufrimiento de las víctimas", implementando estrategias de amplitud de lo memorable y de la capacidad de convocatoria, buscando que la paz no sea el resultado esperado por la evidencia de hechos trágicos, sino el objetivo a alcanzar por la relación de las víctimas y de la ciudadanía con su experiencia histórica, y el esfuerzo consciente por el posicionamiento de causas comunes.

Un instrumento básico en las actividades, transversal, es la cartografía Bogotá, ciudad memoria. En principio, se trata de un instrumento pedagógico diseñado para que la ciudadanía pueda dimensionar lo ocurrido en la capital a lo largo de un periodo que no se considera acabado. Más allá, es un mapa de la ciudad que funciona como magnitud de los muchos casos, hechos, acontecimientos y procesos que son, con o sin reconocimiento formal, irradiadores de patrimonio inmaterial para la paz en la capital, tan recientes como los casos más actuales de abuso y brutalidad policial exacerbados a partir de la pandemia y tan remotos como los acontecimientos del 9 de abril de 1948 y el asesinato de Jorge Eliécer Gaitán. 


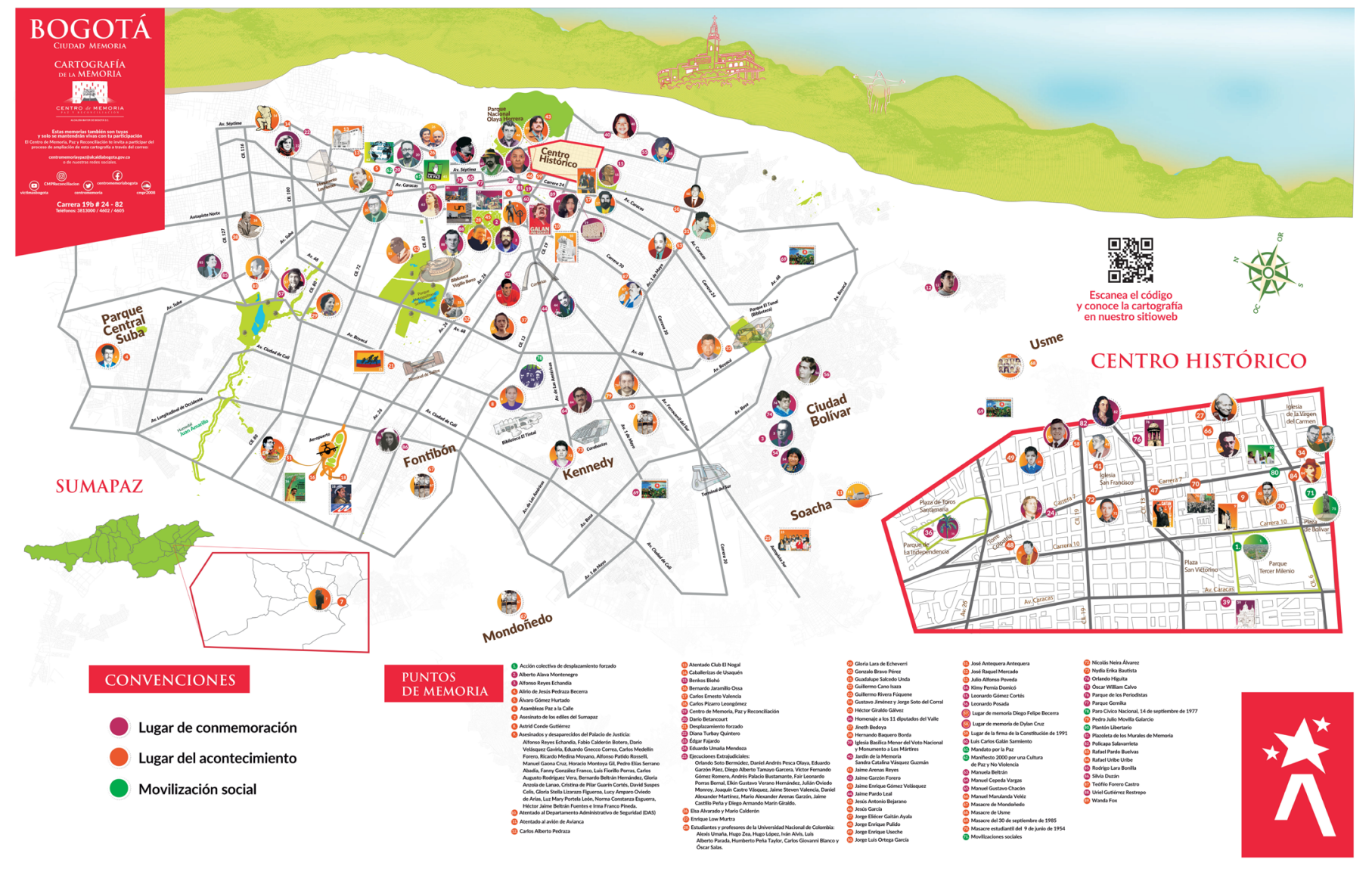

Cartografía Bogotá Ciudad Memoria, con georreferenciación de acontecimientos de violación a los derechos humanos y construcción de paz en la ciudad

Este mapa incluye características interesantes. Por un lado, no es un ejercicio cerrado y se alimenta permanentemente a partir del diálogo y la participación con las víctimas y la ciudadanía; en segundo lugar, está vinculado con sitios, marcas y huellas territoriales en la ciudad de carácter patrimonial como monumentos, placas, nombres de calles, instituciones, colegios, etc. Por último, se construye con un criterio amplio sobre el "capital transmisible de la memoria", de modo que no incluye solo lugares de acontecimientos de vulneración a derechos humanos, sino lugares emblemáticos de movilización social o construcción de paz transgresores.

Este instrumento, si bien no es el único trasversal, es utilizado por las diferentes líneas de trabajo del Centro que se organiza por líneas, insisto, con objetivos y orientaciones ligadas a los planteamientos expuestos:

> Dinamización del Centro:

Al ser un lugar de memoria, esta línea se propone una convocatoria amplia, a las víctimas y la ciudadanía, para la ocupación y uso del Centro como lugar 
físico, al tiempo que acompaña la preservación de lugares de memoria oficiales y no oficiales como monumentos, lugares de conmemoración, etc., que existen en la ciudad por iniciativa de las víctimas y la ciudadanía, todo lo cual se desarrolla en alianza con las instituciones distritales encargadas de la cultura.

Esta línea incluye la exposición central, las exposiciones temporales, la disposición técnica de espacios del Centro, las convocatorias para cursos o talleres de carácter artístico, la coordinación de la agenda de actividades virtuales (fortalecida a partir de la pandemia), y las convocatorias de estímulos para apoyo a proyectos de memoria, paz y reconciliación en la ciudad.

La clave central de esta línea es su trabajo convocante para la movilización ciudadana, lo que se desarrolla a través del ofrecimiento de herramientas y apoyos para la expresión de las víctimas y la ciudadanía, que no pretende nunca ser sustituida por la institucionalidad.

\section{> Gestión del conocimiento:}

Esta línea incluye el desarrollo de investigaciones, el espacio "Diálogos con memoria", la producción de artículos periodísticos, la gestión de archivos documentales, físicos, virtuales, escritos y audiovisuales, la exhibición de películas y documentales, la oferta de servicios archivísticos poscustodiales, y los eventos como seminarios y ciclos en alianza.

La clave de esta línea es la concepción de la memoria en términos explícitamente democráticos, como lo ha planteado Ricard Vinyes (2009), es decir, descentrada del capital transmisible del dolor y el sufrimiento como valor en sí y amplia con respecto a los múltiples factores memorables de la experiencia histórica a considerar para la construcción de la paz.

\section{> Pedagogías de la memoria:}

A través de esta línea se desarrollan procesos pedagógicos dirigidos especialmente a niños, niñas y jóvenes, en alianza con otras instituciones distritales como la Secretaría de Educación y la Secretaría de Integración social, ofreciendo espacios e instrumentos pedagógicos vinculados con la conformación de redes de estudiantes y maestros comprometidos con el impulso de la memoria, la paz y la reconciliación en la ciudad.

En esta línea se desarrollan proyectos vinculados con la Sala "Camino a casa" del Centro, adecuada específicamente para actividades con niños y niñas, producción de material útil para colegios y universidades, bitácoras pedagógicas, cartillas de trabajo e instrumentos de interés de jóvenes como stopmotion, juegos y contenidos para redes sociales. 
Tratándose de una línea dedicada a esta franja poblacional, su clave es, en primer lugar, la afirmación de los derechos y avances posicionados hasta el momento en el país en conexión con objetivos y causas comunes para las nuevas generaciones, especialmente en torno a problemáticas de la humanidad como la crisis climática o los efectos de la nueva revolución de internet y las nuevas tecnologías.

> Memorias locales, sectoriales y poblacionales:

La promoción de la memoria para la construcción de paz implica el fortalecimiento de iniciativas y fuerzas locales, de sectores sociales organizados (docentes) y de poblaciones (indígenas y afros), así como de esfuerzos desde la sociedad civil, artistas y demás promotores. Desde esta línea, se prioriza el apoyo de dichas iniciativas allí donde se desarrollan, en el barrio, la localidad, los ámbitos de movimiento de la sociedad civil y los demás lugares de la ciudad que sirven como irradiadores y convocantes.

De esta manera, desde aquí se impulsan proyectos como Barrios con memoria, donde se incluyen los relatos sobre los procesos de construcción y defensa de territorios, el "poder de lo local" con intercambios con experiencias en otros municipios y ciudades de Colombia y del mundo, el acompañamiento a los proyectos de las propias víctimas ante sus autoridades locales y los demás procesos de participación que se han establecido en la ciudad.

La orientación y el trabajo del Centro de Memoria, Paz y Reconciliación en Bogotá, Colombia, son un aporte al conocimiento sobre la cuestión del patrimonio inmaterial para la resolución de conflictos.

Por supuesto, todo lo anterior implica una perspectiva: el patrimonio inmaterial se considera vivo, como herencia, identidad y fuente de vínculos comunitarios. Para que sea útil, debe ser acción, lo que supone exposición y disposición a la recreación en sus múltiples formas.

En el ámbito de la memoria sobre la violencia política, las violaciones a derechos humanos y las transgresiones y resistencias, esa utilidad implica amplitudes de lo memorable y de quienes han de involucrarse. Supone el cuestionamiento a los efectos automáticos que produce el reconocimiento del pasado de dolor y sufrimiento, tomando en serio la obligación de considerar el presente y el futuro de causas y objetivos comunes desde la diferencia y no solo reafirmaciones de diferencias. 


\section{BIBLIOGRAFÍA}

- Butler, J. (2020) La fuerza de la no violencia. Colombia: Paidós, 2020

- Peterson, J. (2020) Mapas de sentido: una arquitectura de la creencia. Colombia: Planeta

- Rufer, M. (2010) La nación en escenas: memoria pública y usos del pasado en contextos coloniales. México: El Colegio de México

- Vinyes, R. (2009) La memoria como política pública. En: Guixé, J. y Monserrat, I. y (ed). Políticas públicas de la memoria: I Coloquio internacional Memorial Democratic. Barcelona: Milenio Publicaciones, pp. 23-39 